ISSN: 1410-8917

Jurnal Kimia

Sains \&

Aplikasi
Jurnal Kimia Sains dan Aplikasi Journal of Scientific and Applied Chemistry

Journal homepage: http://ejournal.undip.ac.id/index.php/ksa

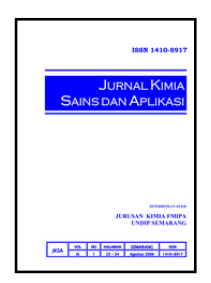

\title{
Sublasi Surfaktan dari Larutan Detergen dan Larutan Detergen Sisa Cucian serta Penggunaannya Kembali sebagai Detergen
}

\author{
Arnelli $^{\mathrm{a}^{*}}$ \\ a Physical Chemistry Laboratory, Chemistry Department, Faculty of Sciences and Mathematics, Diponegoro University, Jalan Prof. \\ Soedarto, Tembalang, Semarang 50275 \\ * Corresponding author: arnelli@live.undip.ac.id
}

\begin{tabular}{|c|c|}
\hline Article Info & Abstract \\
\hline \multirow[t]{2}{*}{$\begin{array}{l}\text { Keywords: } \\
\text { Sublation, } \\
\text { surfactant and } \\
\text { detergency }\end{array}$} & $\begin{array}{l}\text { The sublation process has been performed to obtain the surfactant from the detergent } \\
\text { solution and to determine the effect of impurities on sublation yields to detergent } \\
\text { solution before (pure solution) and after washing process (liquid laundry of laundry). } \\
\text { The results of sublation on the pure solution and the residual wash solution were } 84 \% \\
\text { and } 80 \% \text { respectively with the detergencies of surfactant were } 46.03 \% \text { and } 35.27 \% \text {. With } \\
\text { the addition of } 60 \% \text { sodium tripolyphosphate to the surfactant resulting from the } \\
\text { sublation of the residual wash solution, the detergency obtained was } 74.51 \% \text {. }\end{array}$ \\
\hline & Abstrak \\
\hline $\begin{array}{l}\text { Kata kunci: } \\
\text { sublasi, surfaktan } \\
\text { dan detergensi }\end{array}$ & $\begin{array}{l}\text { Sublasi telah dilakukan untuk mendapatkan surfaktan dari larutan detergen and untuk } \\
\text { mengetahui pengaruh kotoran terhadap hasil sublasi dilakukan sublasi terhadap larutan } \\
\text { detergen sebelum (larutan murni) dan sesudah digunakan untuk proses pencucian } \\
\text { (limbah cair cucian). Hasil sublasi larutan murni dan larutan sisa cucian masing-masing } \\
\text { adalah } 84 \% \text { dan } 80 \% \text {, dengan detergensi masing -masing surfaktan adalah } 46,03 \% \text { dan } \\
35,27 \% \text {. Dengan penambahan } 60 \% \text { natrium tripoli fosfat terhadap surfaktan hasil } \\
\text { sublasi larutan sisa cucian diperoleh detergensi sebesar } 74,51 \% \text {. }\end{array}$ \\
\hline
\end{tabular}

\section{Pendahuluan}

Proses sublasi adalah proses pemisahan senyawa dari campuran berdasarkan adsopsi senyawa tersebut pada gelembung gas dan proses ini lebih unggul dari proses adsorpsi biasa karena hanya surfaktan yang dapat terambil atau dipisahkan [1, 2]

Proses sublasi ini bertujuan untuk mengurangi kandungan surfaktan pada limbah atau untuk menggambil kembali surfaktan dari larutan detergen dan surfaktan yang terambil dapat digunakan kembali. Keberhasilan proses sublasi ini diukur dengan nilai MBAS. Nilai MBAS sebelum dan sesudah reaksi dibandingkan sehingga dapat diketahui recovery surfaktan. MBAS adalah kompleks bahan aktif dengan metilen biru yang bersifat nonpolar dan dapat diekstrak oleh kloroform. Intensitas warna biru dari MBAS dapat diukur dengan spektrofotometer UV-Vis. Reaksi antara surfaktan dengan metilen biru dapat diamati pada gambar 1 berikut [3]:

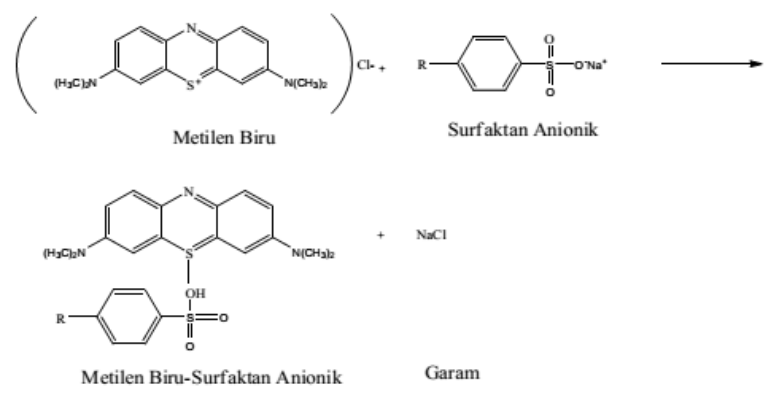

Gambar 1. Reaksi surfaktan dengan metilen biru

Surfaktan dapat dibagi ke dalam beberapa golongan berdasarkan gugus hidrofil yaitu surfaktan anionik, kationik, nonionik dan amfoter. Gugus hidrofob sufaktan anionik terdiri dari rantai lurus 
(terbiodegradasi) dan ada yang bercabang (tak terbiodegradasi).

Contoh:

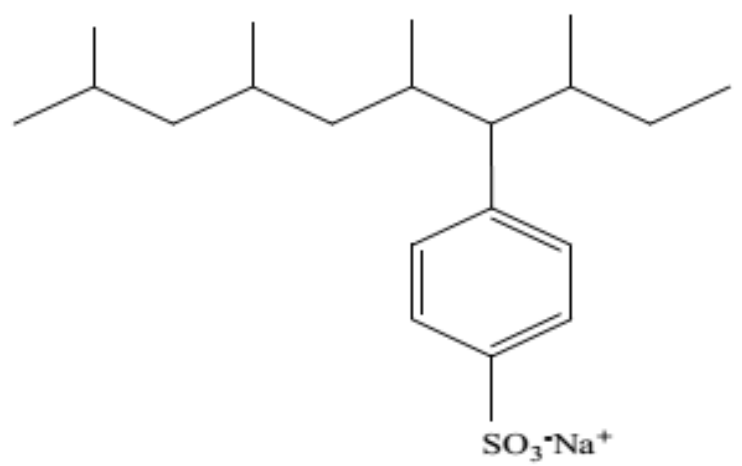

ABS dengan rantai bercabang memiliki kekurangan tidak dapat diuraikan oleh mikroorganise namum sebagian produk detergen masih menggunakan ABS. Pada detergen yang diperdagangkan biasanya mengandung $10-30 \%$ surfaktan [4].

Detergensi adalah sifat spesifik yang dimiliki oleh surfaktan atau zat aktif permukaan untuk membersihkan suatu permukaan dari kotoran [5]. Tetapi zat aktif permukaan tidak dapat membersihkan kotoran dari permukaan dengan sempurna tanpa adanya zat-zat lain sebagai penunjang seperti builder, dan zat aditif, sehingga detergensi diartikan lebih khusus sebagai sifat spesifik yang dimiliki oleh zat aktif permukaan.

Larutan pencuci atau larutan detergen merupakan suatu larutan yang mempunyai sifat membersihkan. Kandungan dari larutan pencuci terdiri dari bahan utama (surfaktan), builder, filler dan aditif. Builder berfungsi meningkatkan efisiensi pencuci dari surfaktan dengan cara menonaktifkan mineral penyebab kesadahan air. Empat kategori builder:

$\checkmark \quad$ Fosfat: sodium tri poly phosphate (STPP) [6]

$\checkmark$ Acetate: nitril tri acetate (NTA), ethylene diamine tetra acetate (EDTA)

$\checkmark \quad$ Silicate: zeolite

$\checkmark \quad$ Citrate: citrate acid

\section{Metode Penelitian}

Penelitian dilakukan dua tahap yaitu tahap sublasi dan tahap dtergensi. Untuk mengetahui senyawa hasil sublasi dilakukan analisis dengan FTIR.

Alat: satu set alat sublasi, Spektofotometer UV-Vis. Spektofotometer FTIR dan peralatan gelas.

Bahan: Detergen, Metilen biru, $\mathrm{H}_{2} \mathrm{SO}_{4}$ pekat, $\mathrm{NaOH}$, $\mathrm{NaCl}, \mathrm{Na}_{3} \mathrm{PO}_{4} \cdot 1 \mathrm{H}_{2} \mathrm{O}$, Indikator pp, Etil asetat teknis, $\mathrm{NaHCO}_{3}$, Gas $\mathrm{N}_{2}$, Kain katun (10x10 cm), Kaolin, Feriklorida, Karbon hitam, Bensin mobil, Lemak sapi, Aseton dan Kloroform teknis
Sublasi

Larutan detergen sebanyak $1000 \mathrm{~mL}$ diambil secara perlahan ke dalam tabung sublator. Ditambahkan 80 gram $\mathrm{NaCl}$ dan $\mathrm{NaHCO}_{3}$ sebanyak 4 gram. Sebanyak 20 $\mathrm{ml}$ etil asetat dialirkan secara perlahan melalui dinding sublator hingga terbentuk lapisan di atas larutan surfaktan. Gas N2 dialirkan ke dalam 100 mL larutan etil asetat yang berada pada tabung lain. Sublasi dilakukan selama 10 menit, setelah itu etil asetat yang berada di atas larutan dipisahkan dari fasa aquades dengan corong pisah. Dilakukan sublasi tiga kali dengan penambahan $50 \mathrm{~mL}$ etil asetat yang baru. Hasil sublasi diuapkan hingga tinggal residu. Selanjutnya residu dilarutkan dan dilakukan analisis MBAS.

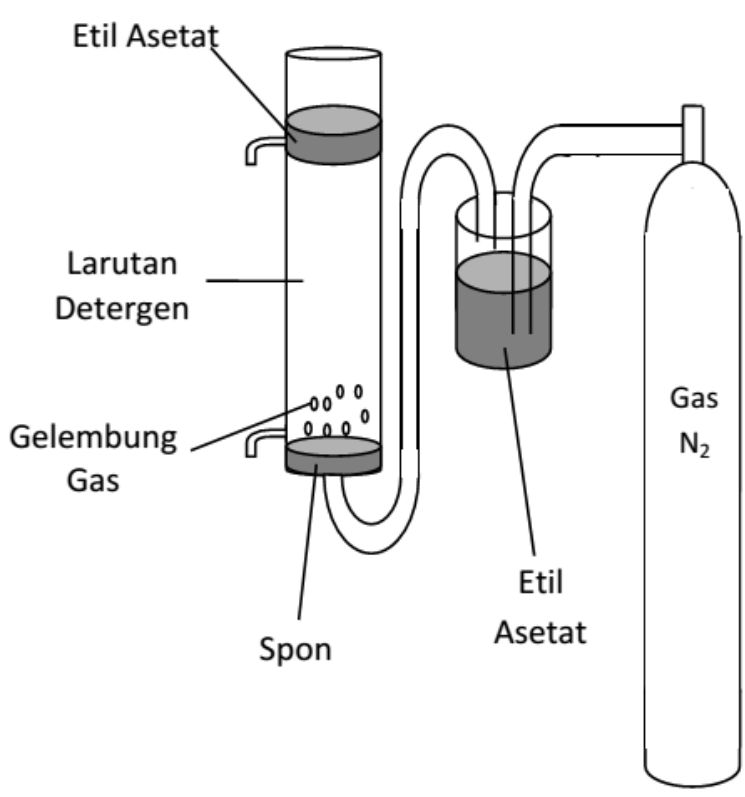

Gambar 2. Skema proses sublasi

\section{Analisis MBAS}

Larutan detergen sebelum sublasi diambil sebanyak $100 \mathrm{~mL}$. Larutan ini kemudian dipindah ke corong pisah dan dinetralkan (ditandai dengan penambahan 2-3 tetes indikator pp, kemudian ditambah $\mathrm{NaOH} 1 \mathrm{~N}$ sehingga larutan berwarna merah muda dan kemudian dihilangkan dengan beberapa tetes $\mathrm{H}_{2} \mathrm{SO}_{4} 1 \mathrm{~N}$ ). Sebanyak $25 \mathrm{~mL}$ larutan metilen biru dan $10 \mathrm{~mL}$ kloroform ditambahkan ke dalam corong pisah dan dikocok selama 30 detik. Larutan kloroform dipisahkan dari fasa air dan fasa air diekstrak kembali dengan $10 \mathrm{~mL}$ kloroform baru sebanyak 2 kali. Semua ekstrak kloroform dicampur dan dicuci dengan $20 \mathrm{~mL}$ larutan pencuci fosfat sebanyak 3 kali. Ekstrak kloroform kemudian diukur absorbansinya dengan menggunakan Spektrofotometer UV-Vis pada panjang gelombang $652 \mathrm{~nm}$. Dilakukan perlakuan yang sama untuk larutan detergen sesudah sublasi.

\section{Analisis FTIR}

Analisis kualitatif surfaktan hasil sublasi larutan produk detergen dilakukan menggunakan spektrofotometer FTIR. Analisis ini digunakan untuk mengetahui gugus-gugus fungsi yang terdapat dalam 
surfaktan hasil sublasi. Kemudian spektra surfaktan hasil sublasi dibandingkan dengan spektra LAS standar.

\section{Uji Detergensi}

Substrat dimasukkan dalam gelas piala $1000 \mathrm{~mL}$ yang berisi kotoran standar sambil diaduk-aduk hingga rata selama 30 menit. Setelah itu substrat diangkat dan diangin- anginkan selama 30 menit. Setelah substrat kering, substrat dioven lagi selama 3 jam hingga diperoleh berat yang konstan dalam suhu 1050C. Substrat dimasukkan desikator selama 1 jam. Substrat kering ditimbang dan dicatat sebagai berat substrat yang telah terkena kotoran, dengan menggunakan rumus sebagai berikut:

$$
P K=\frac{B K K-B B B}{B B B} \times 100 \%
$$

PK:Persen kotoran yang menempel

BKK: Berat substrat kotor

BBB: Berat substrat bersih (awal)

Substrat dioven lagi selama 1 jam. Kemudian substrat dicuci dengan larutan pencuci surfakan hasil sublasi selama setengah jam. Setelah dicuci, substrat dibilas dengan air kran dan diangin-anginkan selama setengah jam. Kemudian substrat dioven selama 3 jam pada suhu $105^{\circ} \mathrm{C}$, dan didesikator selama 1 jam. Substrat yang telah bersih ditimbang dan dicatat berat bersihnya. Persentase kehilangan kotoran dihitung dengan rumus sebagai berikut:

$$
P K^{\prime}=\frac{B K K-B B B^{\prime}}{B B B^{\prime}} \times 100 \%
$$

PK': Persentase pengurangan kotoran

BKK: Berat substrat kotor

BBB': Berat substrat yang sudah dicuci

Kemudian dari data berkurangnya kotoran dan kotoran yang menempel detergensi dapat dihitung. Detergensi $=$

\section{Hasil dan Pembahasan}

Analisis FTIR

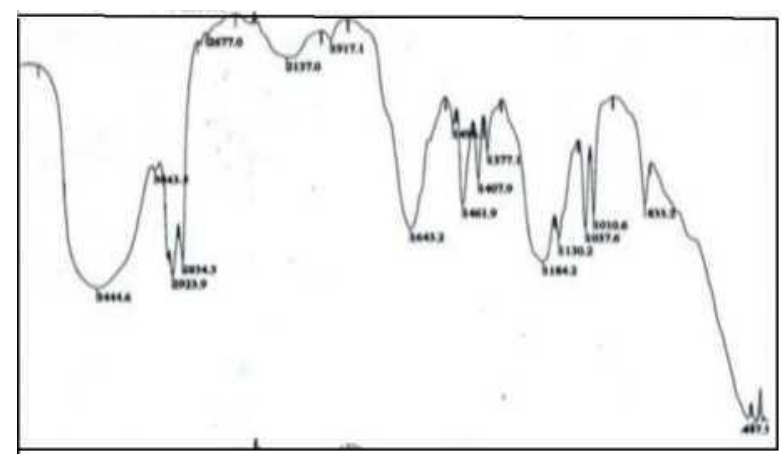

Gambar 3. Spektra FTIR surfaktan hasil sublasi

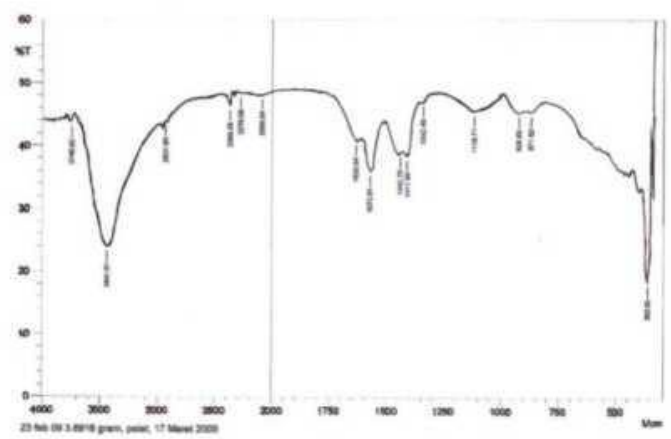

Gambar 4. Spektra FTIR surfaktan hasil sublasi larutan detergen sisa cucian

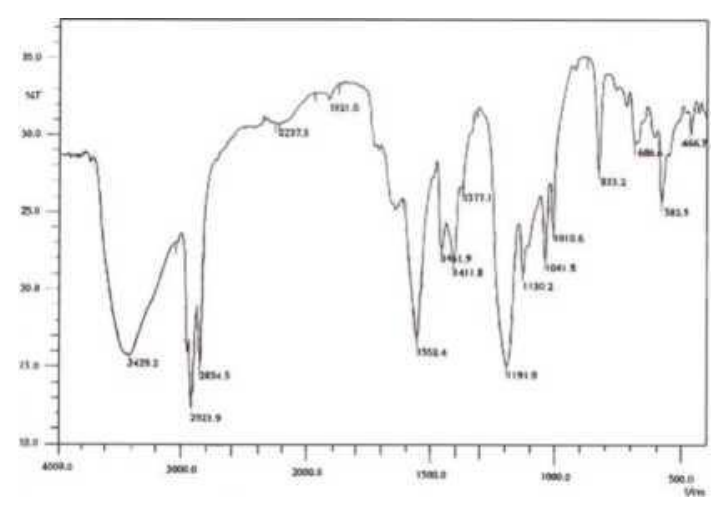

Gambar 5. Spektra FTIR surfaktan LAS

Tabel 1. Identifikasi gugus fungsu

\begin{tabular}{cccc}
\hline Gugus fungsi & $\mathrm{A}\left(\mathrm{cm}^{-1}\right)$ & $\mathrm{B}\left(\mathrm{cm}^{-1}\right)$ & $\mathrm{C}\left(\mathrm{cm}^{-1}\right)$ \\
\hline S=O & 1130,2 & 1411.89 & 1411.8 \\
C=C aromatik & 1643,2 & 1573.91 & 1558.4 \\
Csp3-H & 2923,9 & 2931.80 & 2923.9 \\
Benzene & 1184,3 & 1118.71 & 1191.9 \\
tersubstitusi & & & \\
\hline Keterangan & & &
\end{tabular}

A: Surfaktan hasil sublasi larutan detergen Frekwensi $\left(\mathrm{cm}^{-1}\right)$

B: surfaktan hasil sublasi larutan detergen sisa cucianFrekuensi $\left(\mathrm{cm}^{-1}\right)$

C: surfaktan murni (LAS) Frekuensi $\left(\mathrm{cm}^{-1}\right)$

Berdasarkan hasil analisis di atas dan adanya kesesuaian dari spektra hasil sublasi dengan LAS standar menunjukkan bahwa senyawa yang dihasilkan dari proses sublasi adalah surfaktan jenis LAS.

\begin{tabular}{|c|c|c|c|c|}
\hline No & Sampel & $\begin{array}{c}\text { [MBAS] } 0 \\
(\mathrm{ppm})\end{array}$ & $\begin{array}{c}\text { [MBAS] } \\
\text { sesudah } \\
\text { sublasi }(\mathrm{ppm}) \\
\end{array}$ & $\begin{array}{c}\text { Recovery } \\
(\%)\end{array}$ \\
\hline 1 & $\begin{array}{l}\text { Larutan } \\
\text { Detergen }\end{array}$ & 18,263 & 2,893 & 84,159 \\
\hline 2 & $\begin{array}{c}\text { Larutan } \\
\text { detergen Sisa } \\
\text { cucian }\end{array}$ & 1,169 & 0,942 & 80,58 \\
\hline
\end{tabular}

Analisis MBAS 
Bila dilihat tabel, maka hasil sublasi tidak berbeda secara signifikan, antara sublasi surfaktan larutan detergen murni $(84,159 \%)$ dengan sublasi surfaktan larutan detergen sisa cuian (limbah cair cucian) $(80,59 \%)$, dapat diperkirakan adanya sedikit pengaruh partikel kotoran yang menghambat teradsorpsinya molekul surfaktan pada gelembung gas. Surfaktan bermuatan negatif akan mengikat kotoran yang bermuatan postif sehingga kemampuan surfaktan teradsorpsi pada gelembung gas akan berkurang. Semakin berkurang adsorpsi surfaktan pada gelembung gas maka makin sedikit surfaktan dapat disublasi.

Analisis Detergensi

\begin{tabular}{ccc}
\hline $\begin{array}{c}\text { Surfaktan } \\
\text { Hasil Sublasi }\end{array}$ & $\begin{array}{c}\text { Detergensi } \\
\text { Surfaktan (\%) }\end{array}$ & $\begin{array}{c}\text { Detergensi } \\
\text { Surfaktan }+60 \% \\
\text { Stpp (\%) }\end{array}$ \\
\hline $\begin{array}{c}\text { Larutan } \\
\text { Detergen } \\
\text { Lautan }\end{array}$ & 46,03 & \\
$\begin{array}{c}\text { Detergen Sisa } \\
\text { Cucian }\end{array}$ & 35,27 & 74,51 \\
\hline
\end{tabular}

Pada uji detergensi ini, sodium tripolyphosphat (STPP) berfungsi untuk mengikat unsur-unsur penyebab kesadahan air yang menghalangi berlangsungnya proses pencucian. Jika zat aktif permukaan langsung dilarutkan ke dalam pelarut yang masih mengandung unsur kesadahan tersebut maka zat aktif permukaan akan bereaksi dengan unsur kesadahan yang ada dan zat tersebut berubah menjadi zat yang tidak aktif lagi, sehingga apabila ingin dicapai hasil yang optimal dari keija zat aktif permukaan maka diperlukan penambahan senyawa builder yang mampu mengikat unsur kesadahan tersebut agar tidak mengganggu kerja zat aktif permukaan. Senyawa builder yang digunakan dalam penelitian ini adalah natrium tripolifosfat dan $\mathrm{NaOH} . \mathrm{PO}_{4^{3-}}$ bebas dari natrium tripolifosfat mampu mengikat unsur $\mathrm{Mg}^{2+}$ dan $\mathrm{Ca}^{2+}$ sebagai penyebab kesadahan.

Hal ini disebabkan karena $\mathrm{PO}_{4}^{3-}$ bebas memiliki kemampuan serangan terhadap senyawa $\mathrm{MgCO}_{3}$ dan $\mathrm{CaCO}_{3}$ membentuk ikatan yang lebih kuat dibanding ikatan dari kedua senyawa, serta menjadikan unsurunsur penyebab kesadahan menjadi non aktif. Sehingga STPP dapat berfungsi untuk membantu meningkatkan proses detergensi.

\section{Kesimpulan}

Sublasi surfaktan larutan detergen murni lebih besar dari sublasi surfaktan larutan detergen sisa cucian. Dari spektra FTIR terbukti bahwa proses sublasi dapat memisahkan surfaktan dari campurannya. Detergensi surfakan hasil sublasi surfaktan larutan detergen murni lebih besar dari sublasi surfaktan larutan detergen sisa cucian. Detergensi surfaktan dapat ditingkatkan dengan penambahan $60 \%$ Natrium Tripolifosfat.

\section{Daftar pustaka:}

[1] Young-Sang Kim, Yoon-seok Choi, Won Lee, Extraction Equilibria and Solvent Sublation for Determination of Ultra Trace Bi (III), In (III) and TI (III) in Water Samples by Ion-Pairs of Metal-2Naphthoate Complexes and Tetrabutylammonium Ion, Bulletin of the Korean Chemical Society, 23, 10, (2002)

https://doi.org/10.5012/bkcs.2002.23.10.1381

[2] Clesceri, Greenberg, Trussell, Standard methods for the examination of water and waste water, 17 ed., American Journal of Public Health and the Nations Health, 1989.

[3] Dieter O. Hummel, Identification and analysis of surface-active agents by infrared and chemical methods, Interscience Publishers, 1962.

[4] John Cross, Anionic Surfactants: Analytical Chemistry, Second Edition, Marcel Dekker, Inc, 1998.

[5] Milton .J. Rosen, Surfactants and interfacial phenomena, Wiley, 1978.

[6] Parichat Tanthakit, Ampika Nakrachata-Amorn, John F. Scamehorn, David A. Sabatini, Chantra Tongcumpou, Sumaeth Chavadej, Microemulsion Formation and Detergency with Oily Soil: V. Effects of Water Hardness and Builder, Journal of Surfactants and Detergents, 12, 2, (2009) 173-183 http://dx.doi.org/10.1007/s11743-009-1112-z 